Short Title: SOCIAL GROUP STORIES IN THE MEDIA

\title{
Social Group Stories in the Media and Child Development
}

\author{
Karen E. Dill-Shackleford, Ph.D. \\ Fielding Graduate University \\ Srividya Ramasubramanian, Ph.D \\ Texas A \& M University \\ Elizabeth Behm-Morawitz, Ph.D \\ University of Missouri \\ Erica Scharrer, Ph.D \\ University of Massachusetts-Amherst \\ Melinda C. R. Burgess, Ph.D \\ Southwest Oklahoma State University \\ Dafna Lemish, Ph.D \\ Southern Illinois University-Carbondale
}

Corresponding author: Karen Dill-Shackleford, 2020 De La Vina St., Santa Barbara, CA 93105, (805) 687-1099; kshack@ fielding.edu.

Funding: None.

Financial Disclosure Statement: The authors have no financial relationships relevant to this article to disclose.

Potential Conflicts of Interest: The authors have no conflicts of interest relevant to this article to disclose.

Abbreviations: None. 


\section{Contributors' Statement:}

The working group on portrayals in the media of the Institute for Digital Media and Child Development prepared this document. Karen E. Dill-Shackleford is the group chair. She organized and supervised the research team and wrote the initial draft. All other working group members contributed equally to this project. They edited the draft, adding to the writing and organization. They worked together to identify the key literature, and develop the paper's themes and the recommendations.

\section{Word count: 1744}




\begin{abstract}
How do children and youth come to understand what it means to be a member of a particular race, gender, and other social groups? How do they come to hold beliefs about the groups that they do and do not belong to? Both news stories and fictional narratives that we are tuned into as a culture tell stories about what it means to be a member of a particular social group. In this review article, we relate the latest scientific knowledge on news and entertainment media representations of race, gender and other social categories and what they tell us about how these messages are taken in and processed by developing minds. We include research on identity development, social learning about members of other groups, and both positive and negative behavioral outcomes to cultural messages about race, gender and other social categories. We offer recommendations for stakeholders to understand the role of the media in educating youth about race, gender and other social categories.
\end{abstract}




\section{Social Group Stories in the Media and Child Development}

\section{Background}

Throughout their days, American children and adolescents are increasingly consuming media content. ${ }^{1,2}$ Because we are social creatures for whom relationships are imperative to survival, we seek connections to other people both in the real world and the vicarious world entertainment media offers us. These experiences, whether with real people or fictitious characters, teach us about the social world: how to navigate it, and what others expect, believer and assume about members of social groups_-defined, among others, by race, gender, sexual identity and their intersections. ${ }^{3}$

Quite simply, understanding the nature of the messages children and adolescents receive from the media about both themselves and others as members of various social groups and what effect these messages have on children's and adolescents' thoughts and behaviors is a critical endeavor for anyone working with young people. We live in an age where media are nearly unavoidable. Those who care about children and adolescents are painfully aware of the importance of these mediated realities simply by being exposed to some of the more serious effects of exposure such as eating disorders, sexual harassment, and racial violence. As such, we review research about the nature of media messages about social representations, what effect they have on developing children, and what recommendations can be made regarding responsible media use and production.

\section{Current State}

What is the nature of media messages about social representations? Much research on the issue of social groups and their intersectionalities in the media has taken the form of systematic quantitative content analyses examining how social groups are portrayed. For an 
overview regarding gender see Scharrer ${ }^{4}$ and see Behm-Morawitz and Ortiz ${ }^{5}$ for an overview of race. Generally, media messages about race and ethnicity have a tendency to rely on stereotyped misrepresentations (e.g., the African-American 'gangsta' ubiquitous to video games ${ }^{6}$ ), or a compelling absence notable by exceptions (e.g., lack of representation of Native Americans and Asian Americans in film and television ${ }^{5}$ ). Media portrayals of gender are similarly limited in the nature of representation. Primarily, regardless of genre or target audience demographic, men receive the lion's share of agentic roles while women are primarily valued for their sexuality and appearance. In general, the shared culture that we access through media presents young, White, straight males as the hegemonic or dominant group. Others (e.g., women, non-Whites, LGBTQ individuals) are often marginalized and presented in limited roles. Media are thought to serve as a repository for social group norms and expectancies, and such patterns of representation become normalized for media audiences. ${ }^{5}$

What effect do media messages about social representation have? Research examining the effect of media representations can be categorized in two broad areas. First, how do these representations influence behavioral choices and attitudes about the self? Second, how do these messages influence behavioral choices and attitudes about others? Much of these two areas focus on the poor behavioral choices that potentially limit an individual's options or have the potential to harm.

Impact on the self. Perhaps the most heavily researched area in this domain comes from research examining media portrayals that emphasize beauty ideals and sexualization. ${ }^{7}$ The APA Task Force on the sexualization of girls reported that objectification and sexualization of girls and women is common in a variety of media genres and that exposure to this material by females is related to a host of negative outcomes in the areas of cognitive and physical functioning, body 
dissatisfaction and appearance anxiety, mental health (depression, self-esteem) and sexual wellbeing. ${ }^{8}$ While many who work with adolescents are well aware of the range of problems that can result from identification with these types of images, it is important to understand that negative attitudes about bodies, and a desire to take (unhealthy) behavioral steps to conform to these ideals are seen in children as young as five years of age.

Recent research has found identification with Disney princesses and engagement with related products predicts female gender-stereotyped play that takes place one year later, even after controlling for previously existing gender-stereotyped play, in children $3-61 \frac{1}{2}$ years. ${ }^{9}$ Similar associations exist with exposure to superhero ${ }^{10}$ and gendered television advertising, ${ }^{11}$ illustrating the profound impact of media in shaping children's toy preferences and the nature of their play at a period in which play is so instrumental to social and cognitive development and construction of gender and racial identities.

In terms of identity, a research study found that young Black video gamers were more likely than young White gamers to identify with a same race avatar (White gamers identified equally with same or other race avatars), and to see themselves as similar to that avatar. ${ }^{13}$ Given that most Black avatars in video games are criminals, perhaps it is unsurprising that these gamers experienced significantly lower levels of positive affect following game play. Survey research with African American high school students has shown complex associations between media use and self-esteem. Frequency of viewing sports was negatively associated with three different types of self-esteem (performance, social, and racial), music video viewing was negatively associated with performance self-esteem, and identification with White characters was negatively associated with social self-esteem. ${ }^{14}$ On the other hand, while identification with Black characters was associated with positive appraisals of one's own appearance, there was no 
link between amount of viewing of media with primarily Black casts and self-esteem.

Researchers are just beginning to examine the impact of adopting media personas on developing identities, but enough data exist to be concerned about children of color's developing identities when their social group is represented as either absent or stereotyped. There is evidence from college-students that stereotyped media images can induce stereotype threat, in which members of a negatively stereotyped group underperform consistent with the negative stereotypes $^{14,15}$. Outcomes negatively impacted include academic performance, career choice, ${ }^{14,16}$ disidentification with academics and impaired academic skill building, ${ }^{16}$ as well as hypertension and anxiety. ${ }^{17}$ These are serious concerns for physical and emotional health as well as the developing self.

Impact on others. Researchers have extensively examined how media messages influence our responses to members of various social groups. Mere awareness of the existence of a stereotype linking African Americans and violence predicts a less stringent criterion for deciding to shoot a Black male character in a video game, but not a White male character. ${ }^{18}$ Similar work in regards to harmful choices and gender has found that media exposure is linked to increased acceptance of rape myths ${ }^{19}$ and decreased interest in seeking sexual consent and decreased intentions to honor non-consent. ${ }^{20}$

A number of studies have demonstrated that the way gender, race and other social groups are portrayed in the media can influence attitudes (such as Pro-Black attitudes), feelings (e.g., using a feelings thermometer to measure prejudice), thoughts (e.g., implicit cognition tasks) and behavioral outcomes (e.g., behavioral measures of voting preference) (see, for example, Dill \& Burgess ${ }^{21}$ Ramasubramanian $\&$ Oliver ${ }^{22}$ ) including attitudes towards policy and political judgments. ${ }^{22,23}$ Such studies have uncovered trends for long-term effects and for the importance 
of recency, vividness, and frequency of exposure in influencing thinking about race (see, for example Mastro, Behm-Morawitz \& Ortiz $\left.{ }^{24}\right)$.

Positive Impacts. Recent work calls for the presentation of counter-stereotypes or progressive racial and gender imagery to positively influence stereotypical beliefs. ${ }^{25-30}$ Recent research with children provides evidence that positive media messages reduce prejudice, in part because learning about others, even via media, allows children to see themselves in others. When teachers read fictional stories in which British children were friends with refugee children, prejudice was reduced compared with control children ${ }^{30}$. In another set of studies, children and adolescents read passages from Harry Potter relating to prejudice or a control reading. ${ }^{30}$ Exposure to Harry Potter reduced prejudice towards immigrants, refugees and homosexuals, compared to controls. Both these media reduced prejudice by modeling cross-group friendships and reducing anxiety about cross-group contact.

\section{Future Research}

Future research in media portrayals should: 1) recognize the importance of intersectionalities of social groups, so that multiple aspects of identity (like gender and race) are considered side by side; 2) recognize the importance of social media as well as new and developing media; 3 ) focus on counter-stereotypes as tools to supply more data about positive aspects of media representations; and 4) extend these tools to apply to relational dynamics as well as outcomes studied more frequently. This work should explore media representations with qualitative, quantitative, and critical studies methods. It is imperative that research include full representations of the diverse populations and geographical locations of children and youth, and that special attention be given to comparative studies highlighting both individual differences and social and cultural group differences. 


\section{Recommendations for clinicians, policymakers and educators}

In this paper we have mainly touched upon two aspects of identity, gender and race, although there is research about other important human categories such as ethnic groups, people with disabilities, sexual identity, religious groups, etc. Given that a body of expert research knowledge has catalogued negative effects of negative representations and positive effects of healthy representations of social groups, our first recommendation for the media industry, policymakers, educators, pediatricians, and all other stakeholders is to take seriously that cultural stories shape the lives of children as well as adults: avoid thinking that the ubiquity of media or their entertainment value means that they are trivial or insignificant.

\section{Clinicians and Providers}

Engage in bridging efforts with researchers, policy makers, and educators to provide children with representations of a socially just world that will contribute to their self-image, relationships with others, and well-being and that will contribute to their healthy development as productive members of our society. In addition to recommending limits and suggestions for use, fully explain to parents why and how media matter.

\section{Policy Makers}

Engage in bridging efforts with researchers, the media industry, clinicians and providers, and seek input on policy guidelines from researchers who are publicly engaged in sharing scholarship with diverse audiences in accessible ways.

\section{Educators}

Educators need to invest in media literacy initiatives and curricula and to collaborate with NGOs working for social justice. They should talk to children and teens about how the stories they see tell them who they are and help them to understand where the stories came from and 
what their own role is in determining their destiny. Understand that the content and the frequency of exposure matters in children's development. Find counter-stereotypes and make sure children are exposed to these. Open a dialogue with them about their perspectives. Finally, listen and learn from your children's perspectives. 


\section{References}

1. Christakis DA, Moreno MA. Trapped in the Net: Will Internet Addiction Become a 21stCentury Epidemic? Archives of Pediatrics \& Adolescent Medicine. 2009;163:959-960.

2. The Henry J. Kaiser Family Foundation. Generation M2: Media in the Lives of 8- to 18Year-Olds. 2010. Available at: http://kff.org/other/event/generation-m2-media-in-the-livesof/. Accessed on September 7, 2016.

3. Dill-Shackleford KE. How Fantasy Becomes Reality: Information and Entertainment Media in Everyday Life. 2nd ed. New York: Oxford University Press; 2016.

4. Scharrer EL. Representations of gender in the media. Oxford Handbook of Media Psychology. 2013;(April):267-284. doi:10.1093/oxfordhb/9780195398809.013.0015.

5. Behm-Morawitz E, Ortiz M. Race, ethnicity, and the media. Oxford Handbook of Media Psychology. 2013;(April):252-264. doi:10.1093/oxfordhb/9780195398809.013.0014.

6. Burgess MCR, Dill KE, Stermer SP, Burgess SR, Brown BP. Playing with prejudice: The prevalence and consequences of racial stereotypes in video games. Media Psychology. 2011;14(3):289-311. doi:10.1080/15213269.2011.596467.

7. Zurbriggen EL, Collins RL, Lamb S, et al. APA Task Force on the Sexualization of Girls. Washington, D.C.; 2007.

8. Dohnt H, Tiggemann M. The contribution of peer and media influences to the development of body satisfaction and self-esteem in young girls: a prospective study. Developmental Psychology. 2006;42(5):929-936. doi:10.1037/0012-1649.42.5.929.

9. Coyne, S.M, Linder, J. R., Rasmussen, E. E, Nelson, D. A, \& Birkbeck, V. (2016). Pretty as a princess: Longitudinal effects of engagement with Disney princesses on gender stereotypes, body esteem, and prosocial behavior. Child Development, online advance. DOI: $10.1111 /$ cdev.12569.

10. Coyne, S. M., Linder, J., Rasmussen, E. E., Nelson, D. A., \& Collier, K. M. (2014). It's a bird! It's a plane! It's a gender stereotype!: Longitudinal associations between superhero viewing and gender stereotyped play. Sex Roles, 70, 416-430. doi:10.1007/s11199-0140374-8

11. Pike, J. J., \& Jennings, N. (2005). The effects of commercials on children's perceptions of gender appropriate toy use. Sex Roles, 52, 83-91.

12. Ward, L.M. (2004). Wading through the stereotypes: Positive and negative associations between media use and Black adolescents' conceptions of self. Developmental Psychology, 40(2), 284-294. DOI: 10.1037/0012-1649.40.2.284.

13. Davies PG, Spencer SJ, Quinn DM, Gerhardstein R. Consuming Images: How Television Commercials that Elicit Stereotype Threat Can Restrain Women Academically and Professionally. Personality \& Social Psychology Bulletin. 2002;28(12):1615-1628. doi:10.1177/014616702237644.

14. Davies PG, Spencer SJ, Steele CM. Clearing the air: identity safety moderates the effects of stereotype threat on women's leadership aspirations. Journal of Personality \& Social Psychology. 2005;88(2):276-287. doi:10.1037/0022-3514.88.2.276.

15. Deskins, T., \& Burgess, M.C.R. (2015, May). Video games elicit academic stereotype threat in Black college students, Presented at the annual meeting of the Association of Psychological Science, New York City, NY 
16. Appel M, Kronberger N. Stereotypes and the Achievement Gap : Stereotype Threat Prior to Test Taking. 2012:609-635. Educational Psychology Review. doi:10.1007/s10648-012-92004.

17. Aronson J, Burgess D, Phelan SM, Juarez L. Unhealthy interactions: The role of stereotype threat in health disparities. American Journal of Public Health. 2013;103(1):50-56. doi:10.2105/AJPH.2012.300828.

18. Correll J, Park B, Judd CM, Wittenbrink B. The police officer's dilemma: using ethnicity to disambiguate potentially threatening individuals. Journal of Personality \& Social Psychology. 2002;83(6):1314-1329. doi:10.1037/0022-3514.83.6.1314.

19. Beck VS, Boys S, Rose C, Beck E. Violence against women in video games: A prequel or sequel to rape myth acceptance? J of Interpersonal Violence. 2012;27:3016-3031. doi:10.1177/0886260512441078.

20. Hust SJT, Marett EG, Ren C, et al. Establishing and adhering to sexual consent: The association between reading magazines and college students' sexual consent negotiation. Journal of Sex Research. 2014;51(3):280-290. doi:10.1080/00224499.2012.727914.

21. Dill KE, Burgess MCR. Influence of Black Masculinity Game Exemplars on Social Judgments. Simulation \& Gaming. 2012;44(4):562-585. doi:10.1177/1046878112449958

22. Ramasubramanian S, Oliver MB. Activating and Suppressing Hostile and Benevolent Racism: Evidence for Comparative Media Stereotyping. Media Psychology. 2007;9(3):623646. doi:10.1080/15213260701283244.

23. Ramasubramanian S. The Impact of Stereotypical Versus Counterstereotypical Media Exemplars on Racial Attitudes, Causal Attributions, and Support for Affirmative Action. Communication Research. 2011;38(4):497-516. doi:10.1177/0093650210384854.

24. Mastro D, Behm-Morawitz E, Ortiz M. The Cultivation of Social Perceptions of Latinos: A Mental Models Approach. Media Psychology. 2007;9(2):347-365. doi:10.1080/15213260701286106.

25. Lemish D. Screening Gender on Children's Television: The Views of Producers Around the World. 1st ed. New York; London: Routledge; 2010.

26. Ramasubramanian S. Media-Based Strategies To Reduce Racial Stereotypes Activated By News Stories. Journalism \& Mass Communication Quarterly. 2007;84(2):249-264. doi:10.1177/107769900708400204.

27. Scharrer E, Ramasubramanian S. Intervening in the Media's Influence on Stereotypes of Race and Ethnicity: The Role of Media Literacy Education. Journal of Social Issues. 2015;71(1):171-185. doi:10.1111/josi.12103.

28. Ramasubramanian S. Using celebrity news stories to effectively reduce racial/ethnic prejudice. Journal of Social Issues. 2015;71(1):123-138. doi:10.1111/josi.12100.

29. Vezzali, L., Hewstone, M., Capozza, D., Giovannini, D., \& Wölfer, R. (2014). Improving intergroup relations with extended and vicarious forms of indirect contact. European Review of Social Psychology, 25(1), 314-389, http://doi.org/10.1080/10463283.2014.982948

30. Cameron, L., Rutland, A., Brown, R., \& Douch, R. (2016). Changing Children's Intergroup Attitudes toward Refugees : Testing Different Models of Extended Contact, Child Development, 77(5), 1208-1219. 